\title{
UAV-BASED 3D URBAN ENVIRONMENT MONITORING
}

\author{
Wuttichai Boonpook ${ }^{1}$, Yumin Tan ${ }^{1, *}$, Huaqing Liu ${ }^{2}$, Binbin Zhao ${ }^{2}$, Lingfeng $\mathrm{He}^{1}$ \\ ${ }^{1}$ School of Transportation Science and Engineering, Beihang University, Beijing, China - tanym@ @uaa.edu.cn \\ ${ }^{2}$ China Electric Power Research Institute, Beijing 100192, China
}

\section{Commission ICWG IV/III}

KEY WORDS: DSM, UAV image, change detection, georeferenced data, urban environment monitoring

\begin{abstract}
:
Unmanned Aerial Vehicle (UAV) based remote sensing can be used to make three-dimensions (3D) mapping with great flexibility, besides the ability to provide high resolution images. In this paper we propose a quick-change detection method on UAV images by combining altitude from Digital Surface Model (DSM) and texture analysis from images. Cases of UAV images with and without georeferencing are both considered. Research results show that the accuracy of change detection can be enhanced with georeferencing procedure, and the accuracy and precision of change detection on UAV images which are collected both vertically and obliquely but without georeferencing also have a good performance.
\end{abstract}

\section{INTRODUCTION}

Unmanned Aerial Vehicle (UAV) based remotes sensing system is becoming very useful. It can be used to generate highresolution remote sensing data, Digital Surface Model (DSM), Digital Terrain Model (DTM), Digital Elevation Model (DEM) (Sazak and Savran, 2016) and so on, so it is now widely used in urban monitoring, urban planning in smart city (Sutanta et al., 2016), and it also shows great advantages in construction monitoring, road surface and runoff evaluation, road network planning and landscape changing (Díaz-Vilariño et al., 2016). In urban environment monitoring, 3D change detection based on remote sensing data are needed to detect land use changes or human activities (Chaabouni-Chouayakh et al., 2011; Chaabouni-Chouayakh and Reinartz, 2011).

For UAV-based images georeferencing, generally there are two methods, and the first is known as direct georeferencing, which requires high quality sensors, up to centimeter global navigation satellite system (GNSS) receivers and accurate inertial measurement units (IMU) (Gabrlik, 2015), while the second is known as registration method, which requires Ground Control Points (GCPs), and, the 3D GCPs should be of high positioning accuracy, usually collected by Static GNSS or Real-Time Kinematic (RTK) GNSS. In practice, Hugenholtz et al. (2016) demonstrated that direct georeferencing from onboard Global Positioning System (GPS) without GCPs has lower position and DSM accuracy compared to that from a survey-grade GPS receiver. Similarly, Tan et al. (2016) evaluated high cut slope area from DSM data which is produced from UAV image with and without GCPs, and results show that DSM data without GCPs can be used to detect high cut slope changes in emergency cases.

Qin et al. (2016) gave a fairly complete review on the recent development and applications of 3D change detection, who classified 3D change detection into two rationales: 1) only by geometric comparison; 2) geometric and spectral analysis, which includes the computation of both geometric and spectral information for change analysis. Huang et al. (2017) applied multi-view ZY-3 satellite imagery to precise urban change analysis in a multi-level (pixel, grid, and city block) approach, and Tian et al. (2014) evaluated accuracy of DSM produced from IKONOS stereo imagery and propose a change detection method on height changes and Kullback-Leibler divergence, which confirmed that DSM can be used to improve the accuracy of change detection. Thus, in this research we will use the height difference from geometric comparison for change detection.

Texture analysis is one of the main feature in computer vision, and it has been applied to remote sensing image classification, change detection, and segmentation. Local Binary Pattern (LBP) introduced by Ojala et al. (2002), is proposed as a twolevel version of the texture unit, and it describes the local textural patterns and comparative texture measures with classification based on feature distributions. Pietikainen et al. (2011) also introduced Local Binary Patterns for still images.

In this paper, we will work on images collected from a fixedwing and a Quad-Rotor for 3D urban environment monitoring. The contributions of this work are threefold. First, to evaluate the UAV mapping accuracy with and without georeferenced data from Fixed-wing and Quad-Rotor UAVs. Second, to apply DSM to change detection. Third, to demonstrate DSM and texture-based change detection.

\section{METHODOLOGY}

\subsection{Study area}

Two study areas are selected, and one is in Chongqing and another is in Guangzhou (Figure 1): (a) First study area locates in the agriculture field near Zhujiang river, Guangzhou, which covers around $0.03 \mathrm{~km}^{2}$ with varieties of land use such as bare land, tree, road, and agriculture; (b) Second study area locate in

\footnotetext{
* Corresponding author
} 
the garden of south gate of Yangtze Normal University, Chongqing, and it covers around $0.2 \mathrm{~km}^{2}$ with varieties of land use such as trees, roads, buildings, grass, pool, and bare land.

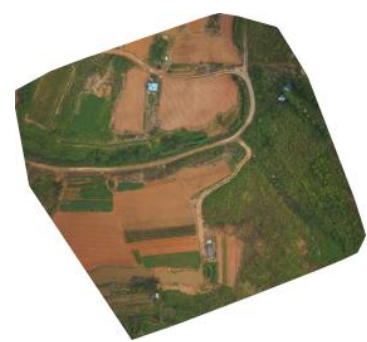

(a)

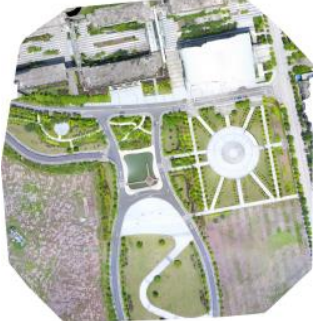

(b)
Figure 1. Study areas (a) Agriculture field in Panyu Qu, Guangzhou (b) Yangzte Normal University, Fuling, Chongqing

\subsection{Data preparation}

The Fixed-wing and Quad-Rotor UAVs used are shown in figure 2. The fixed-wing UAV has the advantages of high ceiling flight, long time fly, multiple sensor installation, high positioning precision and wide area data acquisition. On the other hand, the Quad-Rotor UAV (DJI Phantom4) has the advantage of medium price with extremely device and autonomous flight. The data quality depends on onboard sensor and GPS, and it can capture data in medium and small areas. Thus, this research will evaluate the performance of these UAV platforms for generating DSMs. The difference of onboard capabilities and technology was shown in table 1 .

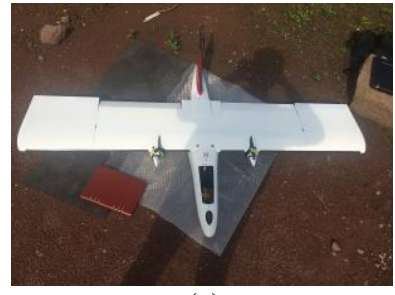

(a)

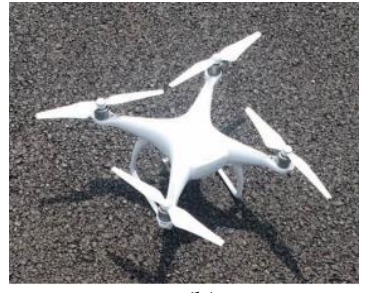

(b)
Figure 2. (a) AI Bird KC-1600 Sky Hawk UAV model and (b) DJI Phantom 4

\begin{tabular}{|c|c|c|}
\hline $\begin{array}{l}\text { UAV properties/ } \\
\text { UAV types }\end{array}$ & Fixed-wing UAV & Quad-Rotor UAV \\
\hline UAV model & $\begin{array}{l}\text { AI Bird KC-1600 } \\
\text { Sky Hawk }\end{array}$ & DJI Phantom 4 \\
\hline Engine & $\begin{array}{l}\text { Two-engine MAV } \\
\text { with } 1.64 \mathrm{~m} \\
\text { wingspan }\end{array}$ & 4 engines \\
\hline Max. ceiling flight & $4 \mathrm{~km}$ & $6 \mathrm{~km}$ \\
\hline $\begin{array}{c}\text { Maximum } \\
\text { time fly }\end{array}$ & $\begin{array}{l}40-60 \text { minutes per } \\
\text { battery }\end{array}$ & $\begin{array}{l}28 \text { minutes per } \\
\text { battery }\end{array}$ \\
\hline $\begin{array}{c}\text { Onboard positioning } \\
\text { system }\end{array}$ & GPS/GLONASS & GPS/GLONASS \\
\hline Camera & SONY ILCE-7R & DJI camera \\
\hline Sensor & $\begin{array}{l}35 \mathrm{~mm} \text { full frame } \\
\text { CMOS sensor }\end{array}$ & $\begin{array}{c}\text { 1/23" CMOS, } \\
\text { effective } \\
\text { pixels: } 12.4 \mathrm{~m}\end{array}$ \\
\hline Lens & $\begin{array}{c}\text { FE } 35 \mathrm{~mm}, \\
\text { f/F2.8/ZA35 }\end{array}$ & $\begin{array}{l}\text { FOV } 94^{\circ} 22 \mathrm{~mm}, \\
\mathrm{f} / 2.8 \text { focus at } \infty\end{array}$ \\
\hline Image size & $7360 \times 4912$ pixels & $4000 \times 3000$ pixels \\
\hline Photo format & JPEG & JPEG \\
\hline
\end{tabular}

Table 1. The different of UAV platforms, onboard capabilities and technology
According to the purpose of analysis, for each study area there will be two flights to collect data. Flight planning was conducted in terms of image content with high overlap. The mission planning was set in following table 2 .

\begin{tabular}{ccc}
\hline Image acquisition & Study area 1 & Study area 2 \\
\hline Flight & First, Second & First, Second \\
Time flight & $9.35 \mathrm{AM}, 10.57 \mathrm{AM}$ & $12.48 \mathrm{AM}, 4.28 \mathrm{PM}$ \\
Covered area & $246 \times 227 \mathrm{~m}$ & $450 \times 480 \mathrm{~m}$ \\
Shooting time & Every 30 second & Every 6 second \\
Operating time & 17 minutes & 40 minutes \\
Max. flight altitude & $200 \mathrm{~m}$ & $50 \mathrm{~m}$ \\
Number of images & 34 images & 255 images \\
Camera orientation & $0^{\circ}$ & $0^{\circ}, 45^{\circ}$ \\
\hline
\end{tabular}

Table 2. Flight and mission planning of this experiment

GCPs were marked and measured with a Trimble R8 GNSS RTK GPS, based on local CORS station, which provided high positioning accuracy in horizontal and vertical. Table 3 shows the GCP properties and data collected.

\begin{tabular}{ccc}
\hline Ground Control Points & & \\
\hline GPS receiver model & A Trimble R8 & A Trimble R8 \\
Horizontal accuracy & $2 \mathrm{~cm}$ & $2 \mathrm{~cm}$ \\
Vertical accuracy & $2 \mathrm{~cm}$ & $2 \mathrm{~cm}$ \\
Number of GCPs & 10 points & 39 points \\
Georeferencing points & 4 points & 9 points \\
Testing points & 6 points & 30 points \\
\hline
\end{tabular}

Table 3. GCP properties and data collected for this experiment

Pix4D mapper is used in this research to generate ortho mosaic, 3D point cloud, DSM, DEM, and DTM. These results can be exported for further manipulation.

\subsection{Data processing}

2.3.1 Fixed-wing UAV mapping: This experiment includes two flights, and in each flight, all images will be divided into two datasets. Moreover, each processing will generate two outputs. The processing flow is shown in figure 3, and the results of ortho image and DSM data are showed in figure 4.

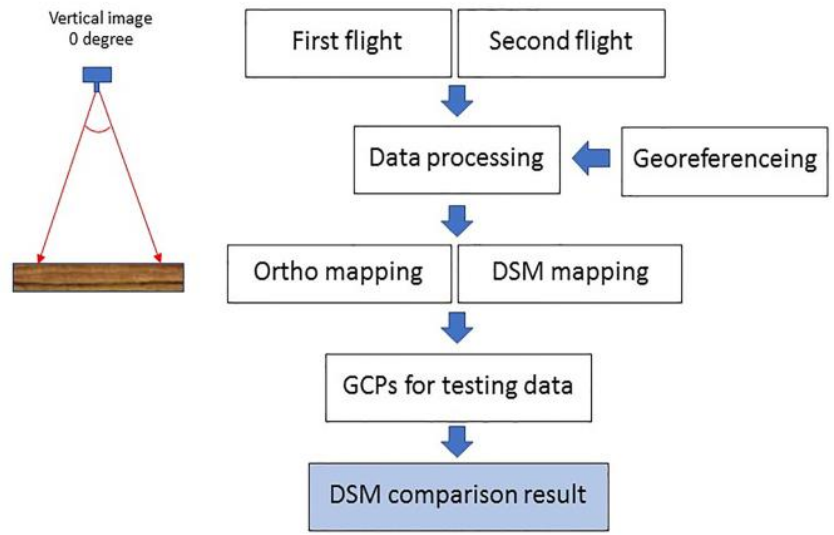

Figure 3. The experiment design of fix-wing UAV 


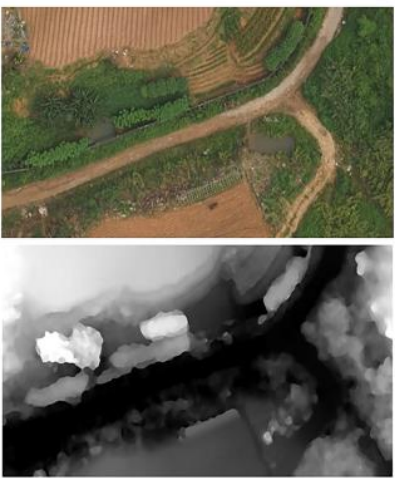

(a)

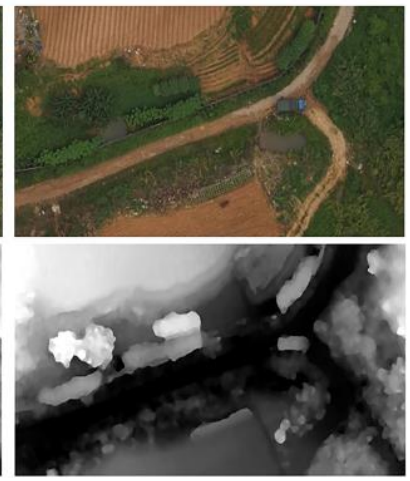

(b)
Figure 4. Ortho mapping and DSM data from first-second flights

2.3.2 Quad-Rotor UAV mapping: This experiment also includes two flights. In each flight, all images are divided into two datasets: vertical images and vertical combined oblique images. Moreover, each dataset will generate two outputs. Finally, there are totally 8 outputs from this experiment, and the processing is shown in figure 5 . the results of ortho image and DSM data are shown in figure 6.

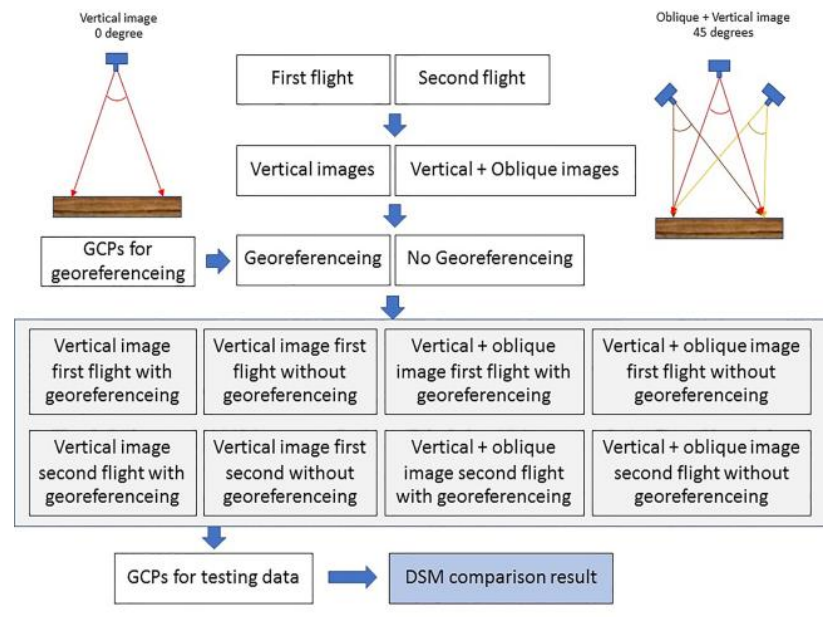

Figure 5. The experiment design of Quad-Rotor UAV

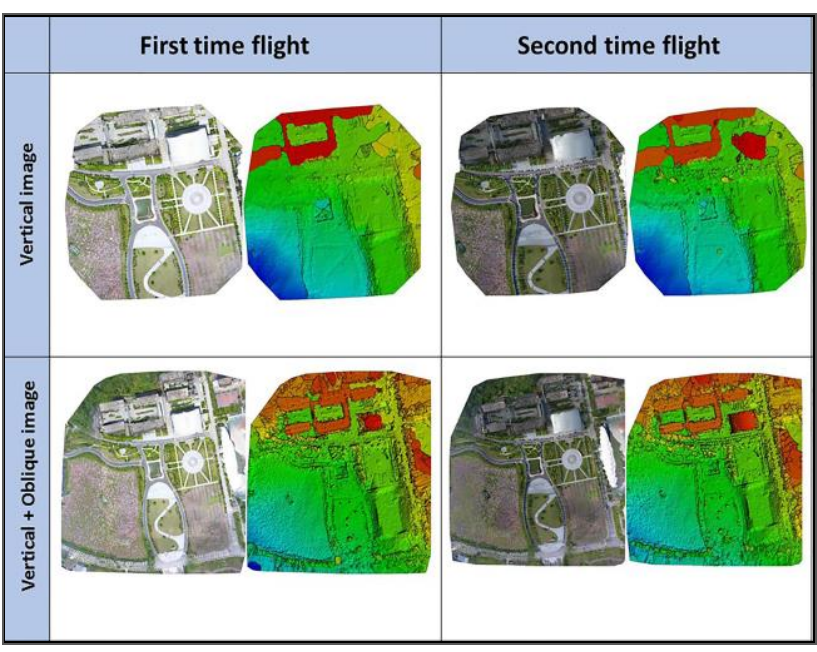

Figure 6. Ortho mapping and DSM data of first-second flights.

\subsection{Accuracy Assessment}

2.4.1 Fixed-wing mapping: The accuracy assessment of ortho images and DSMs is by 4 GCPs. Measurements follow the recommended standard of digital ortho imagery accuracy by American Society for Photogrammetry and Remote Sensing (ASPRS) positional accuracy standard (ASPRS, 2015). The results of first- and second-time mappings shows that horizontal accuracy has RMSEX and RMSEY within 1-pixels, which is recommended in work of highest accuracy, and vertical accuracy for digital elevation data has absolute accuracy of RMSEz in non-vegetated at $95 \%$ confidence level. The RMSE $\mathrm{X}, \mathrm{Y}, \mathrm{z}$ are shown in table 4 and average Ground Sampling Distance (GSD) is $2.84 \mathrm{~cm}$.

\begin{tabular}{lcccc}
\hline \multirow{2}{*}{ UAV mapping } & \multicolumn{4}{c}{ Georeferenced RMS Error (M) } \\
\cline { 2 - 5 } & Mean & $\mathrm{X}$ & $\mathrm{Y}$ & $\mathrm{Z}$ \\
\hline First flight mapping & 0.03 & 0.0202 & 0.0126 & 0.0587 \\
$\begin{array}{l}\text { Second flight } \\
\text { mapping }\end{array}$ & 0.02 & 0.0135 & 0.0152 & 0.0485 \\
\hline
\end{tabular}

Table 4. Map accuracy of fix-wing UAV

2.4.2 Quad-Rotor mapping: The accuracy assessment of ortho mapping and DSM data is with $30 \mathrm{GCPs}$, and measurement also follow the digital ortho imagery accuracy in ASPRS positional accuracy standard. Results of first- and second-time mappings show that horizontal accuracy has RMSEx and RMSEy over 1-pixels, which is recommended in standard mapping and GIS work, and vertical accuracy for digital elevation data has absolute accuracy of RMSEz in nonvegetated at $95 \%$ confidence level. The average GSD is 3.40 $\mathrm{cm}$. In contrast, both vertical combined oblique images of firstand second-time mapping have horizontal accuracy in RMSEX and RMSEY less than 1-pixel which is recommended in highest accuracy work, and vertical accuracy has absolute accuracy of $\mathrm{RMSE}_{z}$ in non-vegetation level. The average GSD is $4.6 \mathrm{~cm}$. The RMSE X, Y, $\mathrm{Z}$ are shown in table 5.

\begin{tabular}{lcccc}
\hline \multirow{2}{*}{ UAV mapping } & \multicolumn{5}{c}{ Georeferenced RMS Error (M) } \\
\cline { 2 - 5 } & Mean_E & $\mathrm{X}$ & $\mathrm{Y}$ & $\mathrm{Z}$ \\
\hline $\begin{array}{l}\text { Vertical image in } \\
\text { first-time mapping }\end{array}$ & 0.0330 & 0.0451 & 0.0399 & 0.0191 \\
$\begin{array}{l}\text { Vertical image in } \\
\text { second-time mapping }\end{array}$ & 0.0410 & 0.0490 & 0.0415 & 0.0218 \\
$\begin{array}{l}\text { Vertical combined } \\
\text { oblique image in } \\
\text { first-time mapping }\end{array}$ & 0.0172 & 0.0256 & 0.0170 & 0.0090 \\
$\begin{array}{l}\text { Vertical combined } \\
\text { oblique image in } \\
\text { second-time mapping }\end{array}$ & 0.0275 & 0.0327 & 0.0364 & 0.0133 \\
\hline
\end{tabular}

Table 5. Map accuracy of Quad-rotor UAV

2.4.3 Accuracy of ortho mapping and DSM data compared with testing GCP: The ortho mapping and DSM data will be evaluated with 30 referencing points from RTKGNSS. The result of absolute accuracy of horizontal and vertical are shown in table 6 . In vertical image, both first- and second-time mapping have over 1-pixels standard level of horizontal and vertical accuracy, but it is less than $95 \%$ 
confidence level. On the other hand, vertical combined oblique image, both first- and second-time mapping have horizontal and vertical accuracy less than 1-pixels standard.

\begin{tabular}{lccc}
\hline \multirow{2}{*}{ UAV mapping } & \multicolumn{3}{c}{ Georeferenced RMS Error (M) } \\
\cline { 2 - 4 } & $\mathrm{X}$ & $\mathrm{Y}$ & $\mathrm{Z}$ \\
\hline $\begin{array}{l}\text { Vertical image in first-time } \\
\text { mapping }\end{array}$ & 0.0366 & 0.0460 & 0.0427 \\
$\begin{array}{l}\text { Vertical image in second- } \\
\text { time mapping }\end{array}$ & 0.0221 & 0.0349 & 0.0440 \\
$\begin{array}{l}\text { Vertical combined oblique } \\
\text { image in first-time mapping }\end{array}$ & 0.0006 & 0.0068 & 0.0468 \\
$\begin{array}{l}\text { Vertical combined oblique } \\
\text { image in second-time } \\
\text { mapping }\end{array}$ & 0.0009 & 0.0009 & 0.0413 \\
\hline
\end{tabular}

Table 6. Showing the root mean square error $\mathrm{X}, \mathrm{Y}, \mathrm{Z}$ of georeferenced mapping

2.4.4 To evaluate the accuracy of ortho mapping and DSM data without georeferencing: To evaluate the positioning accuracy without GCPs georeferencing, RMS error from 30 testing points are calculated. Position errors of every testing point are measured, and the overall accuracy is calculated and shown in table 7. The result shows that horizontal error of vertical image first- and second-time mappings have distortion error about 7.8063 and 7.7430 meters, and vertical combined oblique image of first- and second-time mappings have distortion about 4.9651 and 1.9026 meters. Moreover, vertical error, vertical of image first- and secondtime mappings have error about 11.0257 and 55.4621 meters, and vertical combined oblique image of first- and second-time mapping have error about 17.2366 and 55.0557 meters respectively. RMS Error without georeferenced mapping recommended use in visualization and less accuracy work.

\begin{tabular}{lcccc}
\hline \multirow{2}{*}{ UAV mapping } & \multicolumn{4}{c}{ Without Georeferenced RMS Error (M) } \\
\cline { 2 - 5 } & $\mathrm{X}$ & $\mathrm{Y}$ & $\mathrm{D} \_$Error & $\mathrm{Z}$ \\
\hline $\begin{array}{l}\text { Vertical image in } \\
\text { first-time mapping }\end{array}$ & 3.2078 & 7.1167 & 7.8063 & 11.0257 \\
$\begin{array}{l}\text { Vertical images in } \\
\text { second-time mapping }\end{array}$ & 4.7494 & 6.1153 & 7.7430 & 55.4621 \\
$\begin{array}{l}\text { Vertical combined } \\
\text { oblique image in } \\
\text { first-time mapping }\end{array}$ & 2.0908 & 4.5034 & 4.9651 & 17.2366 \\
$\begin{array}{l}\text { Vertical combined } \\
\text { oblique image in } \\
\text { second-time mapping }\end{array}$ & 0.7885 & 1.7315 & 1.9026 & 55.0557 \\
\hline
\end{tabular}

Table 7. Showing the root mean square error $\mathrm{X}, \mathrm{Y}, \mathrm{Z}$ and distant error of no georeferenced mapping

2.4.5 Map distortion: Mosaicking process will distort images, and the level of map distortion depends on the quality of the original images. Distortion can be got by computing the distance between the marked points on mapping and the referenced points from RTK-GNSS which should has the same location. The image distortion was presented by RMS Error (the more different, the larger distortion). All the RMS Error of distortions are less than 1 meter, as shown in table 8 .

\begin{tabular}{lc}
\hline \multicolumn{1}{c}{ UAV mapping } & RMS Error (M) \\
\hline $\begin{array}{l}\text { Comparing GCPs and Vertical image in } \\
\text { first-time mapping }\end{array}$ & 0.6622 \\
$\begin{array}{l}\text { Comparing GCPs and Vertical image in } \\
\text { second-time mapping }\end{array}$ & 0.8144 \\
$\begin{array}{l}\text { Comparing GCPs and Vertical combined } \\
\text { oblique image in first-time mapping }\end{array}$ & 0.0781 \\
$\begin{array}{l}\text { Comparing GCPs and Vertical combined } \\
\text { oblique image in second-time mapping }\end{array}$ & 0.2411 \\
\hline
\end{tabular}

Table 8. Showing image distortion comparing between GCPs and testing point

\subsection{Change detection}

2.5.1 Change detection algorithm: This algorithm is by combination of height difference and texture analysis. The first step is to conduct DSM change detection. After the filtering operation on DSMs by Gaussian smoothing, the height difference $(H)$ is calculated from two DSMs. The changed area will be defined within the range of thresholds $\left(H_{t h}\right)$ including 1 is changed and 0 is no changed. The equation is shown in equation (1).

$$
H_{t h(i, j)}= \begin{cases}0, & x>H ; x<-H \\ 1, & -H \leq x \leq H\end{cases}
$$

where $\quad H_{t h(i, j)}=$ the range of threshold 0,1 of pixel $(i, j)$

$H=$ height different value

$x=$ the range of changed area

Second step is to conduct texture-based change detection. Uniform Local Binary Pattern $\left(\mathrm{LBP}^{\mathrm{U} 2}\right)$ is used to calculate texture difference. The LBP texture operator has original $3 \times 3$ neighbourhood which is threshold at the center of kernel. There are 8 neighbouring pixels and perform 8 comparisons. Each comparison will calculate two pixels between center and neighbour pixel. If the center pixel value is greater or equal to neighbouring pixel value, it will set to 1 . Else if the center pixel value is less than the neighbouring pixel value, it will set to 0 . Then each comparison will iterate in the counter-clockwise direction and multiplied by binomial weights. All neighbouring comparison will be calculated in equation (2). The Uniform mapping produces 59 output labels. In processing, kernel will move around and save these results into $\mathrm{LBP}^{\mathrm{U} 2}$ image as $\mathrm{R}_{L B P}$, $\mathrm{G}_{L B P}, \mathrm{~B}_{L B P}$.

$$
L B P_{P, B(i, j)}=\sum_{P=0}^{P-1} s\left(g_{p}-g_{c}\right) 2^{P}
$$

where $\quad L B P_{P, B}(i, j)=$ Uniform $L B P$ value of pixel $(i, j)$

$S_{()}=$the different of invariant changes of the images

$P=$ the total number of involved neighbours

$B=$ the radius of the neighbourhood

$g_{c}=$ the value of the center pixel

$g_{p}=$ the value of its neighbours

Texture based change detection is calculated from the pairwise distance between two $\mathrm{LBP}^{\mathrm{U} 2}$ images following equation (3). This equation calculates arccos from two $\mathrm{LBP}^{\mathrm{U} 2}$ images and the result value will plot on histogram. The texture changed will defined by the range of thresholds $\left(L_{t h}\right)$ value including texture 
changed, which has $L_{(i, j)}$ more than $L_{t h}$ (set to 1) and no change, which has $L_{(i, j)}$ less than $L_{t h}$ (set to 0 ).

$$
L_{(i, j)}=\arccos \left(\frac{A_{1}^{*} A_{2}}{\left|A_{1}\right|\left|A_{2}\right|}\right)
$$

where $\quad L_{(i, j)}=$ the range of cosine distance from pixel $(\mathrm{i}, \mathrm{j})$ $A_{l}=$ the pixel value of LBP image 1 $A_{2}=$ the pixel value of LBP image 2

DSM and texture-based change detection will be defined changed area as three conditions: 1) Changed area, it means that the plus value of same positioning between height change value $\left(H_{t h}(i, j)\right)$ and LBP changed value $\left(L_{(i, j)}\right)$ equal to $\left.2 ; 2\right)$ changed in one condition, it means that other plus values equal to 1 . It will be defined as changed area with one condition; 3) No changed area, it means that the plus values equal to 0 , that will be defined as no changed area. The equation is shown in equation (4)

$$
H_{t h(i, j)}+L_{(i, j)}=\left\{\begin{array}{l}
2, \text { Changed area } \\
1, \text { Changed in one condition } \\
0, \text { No changed area }
\end{array}\right.
$$

where $\quad H_{t h(i, j)}=$ height different thresholds of pixel $(\mathrm{i}, \mathrm{j})$ $L_{(i, j)}=$ LBP changed thresholds of pixel $(\mathrm{i}, \mathrm{j})$

2.5.2 DSM data preparation: Change detection computes the difference of two mappings. In this function, map positioning $(\mathrm{X}, \mathrm{Y})$ and height value $(\mathrm{Z})$ of the two mappings should have surface fitting. To deal with no referenced data, this research applied image to image registration to fit both mapping in horizontal positioning. At the first stage, the firsttime mapping without georeferenced is taken as the reference image and second-time image without georeferencing as the image to be adjusted. The following step is to adjust vertical positioning by computing height difference of 30 reference points. The evaluation of vertical error is shown in table 7 . Then RMSEz are used to adjust height difference to fit the surface mappings in vertical position.

2.5.3 DSM change detection: Geometric comparison is made to calculate height difference of two co-registered DSMs, which is done in ENVI. Results by Fixed-wing UAV is shown in figure 7, and we can see that the changed area includes a car, shade of tree, and water level in pool.

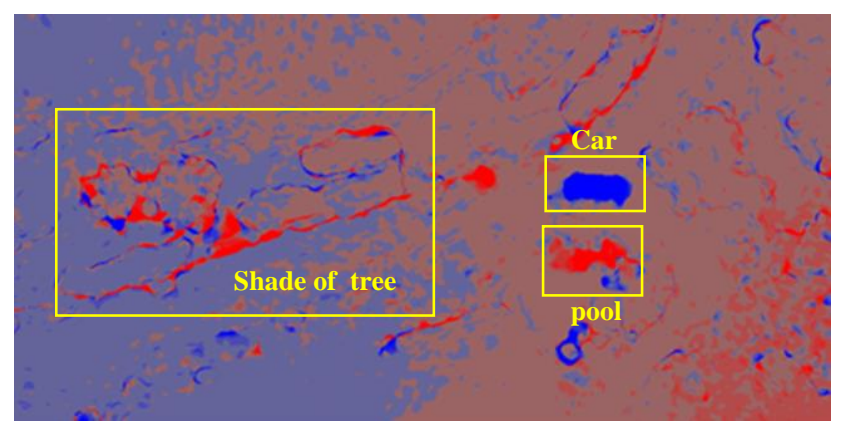

Figure 7. DSM change detection from fixed-wing UAV

Quad-Rotor UAV results as shown in figure 8: the top-left map, which is vertical images with georeferenced mapping, can detect changed objects (cars) and height difference (trees). Moreover, the top-right map, which is vertical combined with oblique images and georeferenced mapping, has higher accuracy on DSM change detection with less error on height difference of trees and surface fitting. On the other hands, the bottom-left map, vertical images without georeferenced mapping has error on DSM change detection because of the different of surface fitting and map orientation between two DSM maps. However, vertical combined oblique images without georeferenced mapping, the bottom-right map, can produce DSM change detection more accurate on surface fitting or map orientation comparing with vertical image without georeferenced mapping. With these experiments, it can be summarized that vertical combine oblique mapping has higher accuracy on DSM change detection comparing with vertical mapping, and vertical combined oblique images without georeferenced mapping can be used to detect changed area for inaccessibility areas.

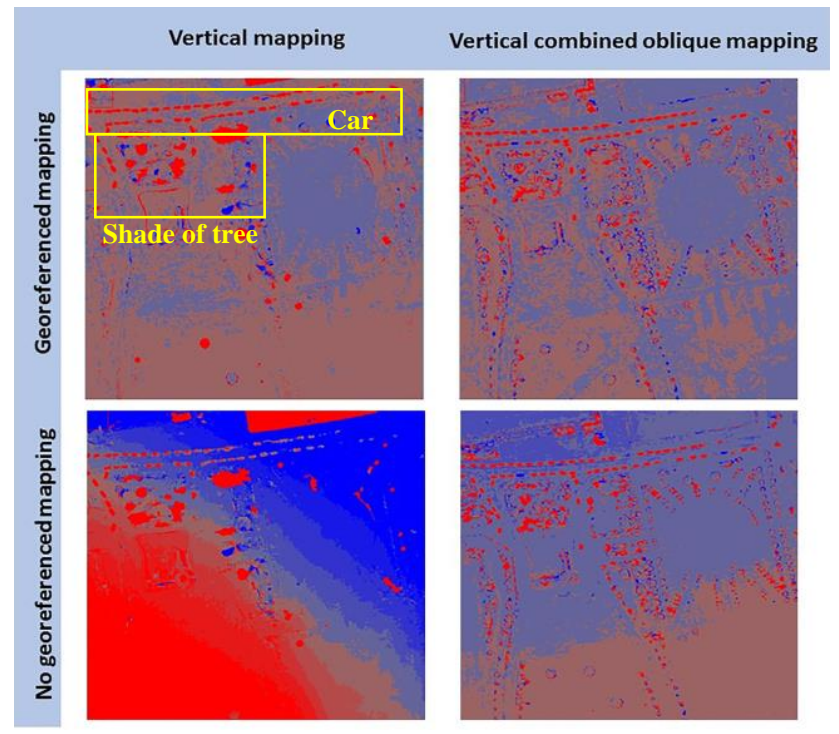

Figure 8. DSM mapping change detection

2.5.4 DSM and texture-based change detection: The experiment of fixed-wing UAV mapping for DSM and texturebased change detection is shown in figure 9. The visual of changed objects from (a) first-time mapping and (b) secondtime mapping is car. As the steps of this processing, first step will calculate height difference from DSM. The result is shown in (c) that there are some errors on shade of tree, water level, and grass. Second step will calculate texture-based change detection. The result is shown in (d) that there is some error on shadow and intensity of colour. Last step will evaluate DSM and texture-based change detection. The result is shown in (e) illustrated that this method can detect changed object (car) from two-time mappings.

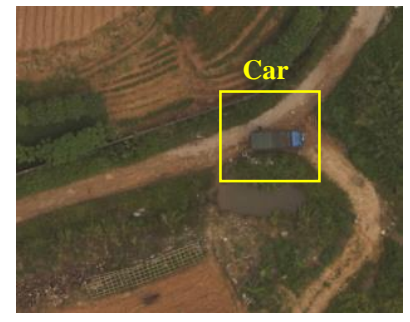

(a)

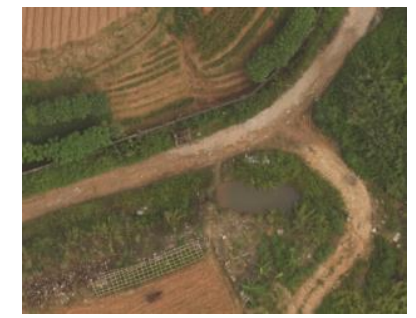

(b) 


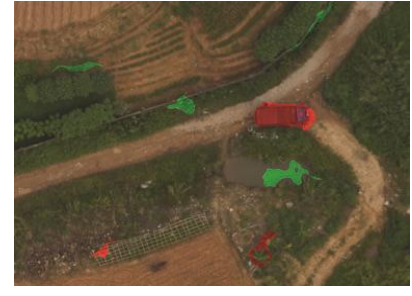

(c)

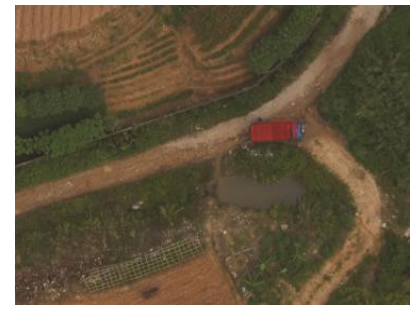

Label

Changed area

Changed in one condition

(e)

Figure 9. The step of DSM and texture based change detection result from Fixed-wing UAV

The result of DSM and texture-based change detection from Fixed-wing UAV mapping is better. To evaluate the performance of previous change detection method, this experiment will use Quad-Rotor UAV to capture images in new study area (the garden of Yangtze Normal University) and take the advantage of camera orientations to capture in vertical and oblique angles. The result of DSM and ortho mapping from Quad-Rotor UAV proposes to evaluate this change detection method. The different objects in this study area are cars and motorcycles as shown in figure (a) and figure (b). In the experiment design, this process defined 3 conditions of input data, such as vertical image with georeferenced mapping and vertical combined oblique images with georeferenced mapping, vertical combined oblique images without georeferenced mapping. The result of DSM and texture based change detection are shown in figure 10 that: 1) vertical image with georeferenced mapping has low accuracy to detect changed object, which has error in shadow and building area as shown in figure (c) ; 2) vertical combined oblique images with georeferenced mapping has a good accuracy on change detection method with less error in shadow area as shown in figure (d) ; 3) vertical combined oblique images without georeferenced mapping cannot detect changed objects due to the errors of surface fitting and shadow area showing in figure (e).

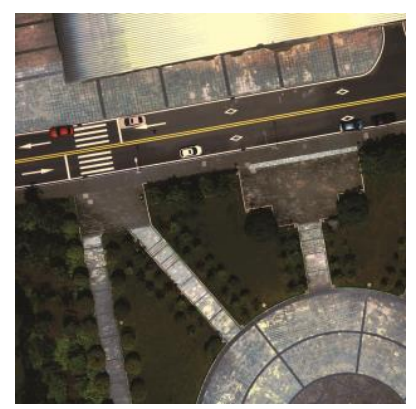

(a)

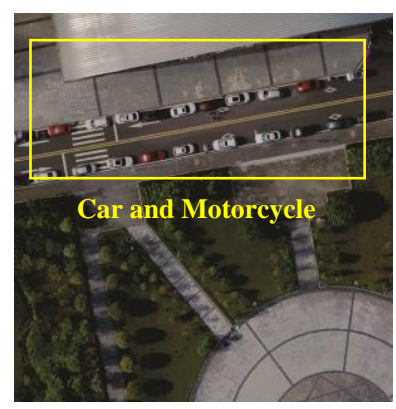

(b)

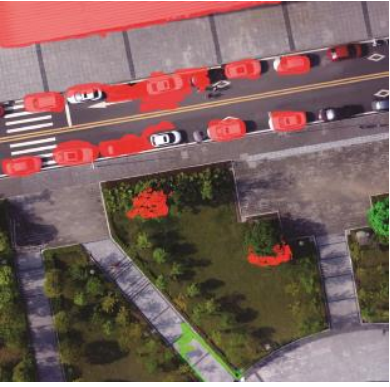

(c)

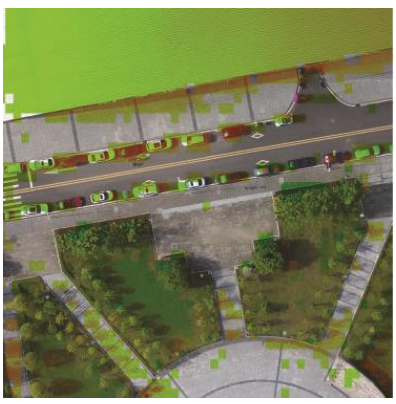

(e)

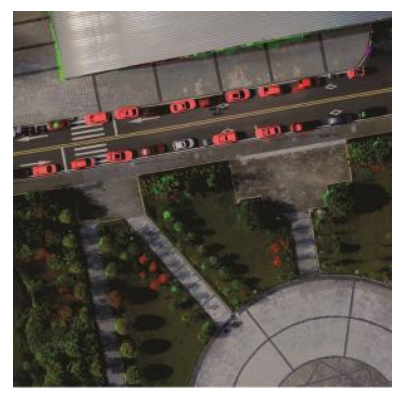

(d)
Label

Changed area

Changed in one condition
Figure 10. DSM and texture based change detection result from Quad-Rotor UAV

\section{CONCLUSION AND DISCUSSION}

In this research fixed-wing UAV and quad-rotor UAV are both used to collect images, and processing results show that ortho image and DSM georeferenced with GCPs of high position accuracy can reach enough horizontal mapping accuracy even for work of very high requirement in accuracy. As to the mapping accuracy comparation of different camera orientations, result show that vertical image produces ortho image and DSM with highest accuracy, and DSM produced from vertical and oblique images has a good surface fitting and 3D shape of object. However, the most important criteria for producing ortho image and DSM with high position accuracy is GCPs.

In case of DSM mapping without georeferencing for change detection, result shows that DSM change detection from vertical mapping has limitation on map orientation and 3D shape. Although vertical mapping has high position accuracy, vertical combined oblique mapping can produce less position error both horizontally and vertically. The proposed change detection method by combining DSM and LBP-based texture proved its good performance. So, in cases where the requirement in position accuracy is not very high, vertical combined with oblique UAV mapping can be used to make change detection.

\section{ACKNOWLEDGEMENTS}

This work is funded by State Grid Scientific Project 2016 (No. GCB17201600036) "Research on data processing theory and methods of the auxiliary lines selection based on satellite remote sensing image". The authors would like to thank the anonymous reviewers for their constructive comments on this paper. 


\section{REFERENCES}

American Society for Photogrammetry and Remote Sensing (ASPRS), 2015. ASPRS Positional Accuracy Standards for Digital Geospatial Data. Photogramm. Eng. Remote Sens. 81, 1-26. https://doi.org/10.14358/PERS.81.3.A1-A26

Chaabouni-Chouayakh, H., D’Angelo, P., Krauss, T., Reinartz, P., 2011. Automatic urban area monitoring using digital surface models and shape features. $2011 \mathrm{Jt}$. Urban Remote Sens. Event 85-88. https://doi.org/10.1109/JURSE.2011.5764725

Chaabouni-Chouayakh, H., Reinartz, P., 2011. Towards Automatic 3D Change Detection inside Urban Areas by Combining Height and Shape Information. Photogramm. Fernerkundung - Geoinf. 2011, 205-217.

https://doi.org/10.1127/1432-8364/2011/0083

Díaz-Vilariño, L., González-Jorge, H., Martínez-Sánchez, J., Bueno, M., Arias, P., 2016. Determining the limits of unmanned aerial photogrammetry for the evaluation of road runoff. Meas. J. Int. Meas. Confed. 85, 132-141.

https://doi.org/10.1016/j.measurement.2016.02.030

Gabrlik, P., 2015. The use of direct georeferencing in aerial photogrammetry with micro UAV. IFAC-PapersOnLine 28, 380-385. https://doi.org/10.1016/j.ifacol.2015.07.064

Huang, X., Wen, D., Li, J., Qin, R., 2017. Multi-level monitoring of subtle urban changes for the megacities of China using high-resolution multi-view satellite imagery. Remote Sens. Environ. 196, 56-75.

https://doi.org/10.1016/j.rse.2017.05.001

Hugenholtz, C., Brown, O., Walker, J., Barchyn, T., Nesbit, P., Kucharczyk, M., Myshak, S., 2016. Spatial accuracy of UAVderived orthoimagery and topography: Comparing photogrammetric models processed with direct geo-referencing and ground control points. Geomatica 70, 21-30. https://doi.org/10.5623/cig2016-102

Ojala, T., Pietikainen, M., Maenpaa, T., 2002. Multiresolution gray-scale and rotation invariant texture classification with local binary patterns. IEEE Trans. Pattern Anal. Mach. Intell. 24, 971-987. https://doi.org/10.1109/TPAMI.2002.1017623

Pietikäinen, M., Hadid, A., Zhao, G., Ahonen, T., 2011. Computer Vision Using Local Binary Patterns. https://doi.org/10.1007/978-0-85729-748-8

Qin, R., Tian, J., Reinartz, P., 2016. 3D change detection Approaches and applications. ISPRS J. Photogramm. Remote Sens. 122, 41-56.

https://doi.org/10.1016/j.isprsjprs.2016.09.013

Sazak, S., Savran, D., 2016. Three Dimensional Digital Terrain Model Approach for the Projection of Urban Silhoutte - The Case of Edirne. Procedia - Soc. Behav. Sci. 225, 226-238. https://doi.org/10.1016/j.sbspro.2016.06.022

Sutanta, H., Aditya, T., Astrini, R., 2016. Smart City and Geospatial Information Availability, Current Status in Indonesian Cities. Procedia - Soc. Behav. Sci. 227, 265-269. https://doi.org/10.1016/j.sbspro.2016.06.070

Tan, Y., He, L., Bai, L., 2016. Precision Assessment of UAVRS Based DSM in Disaster Emergency. Adv. Remote Sens. 5, 203213.
Tian, J., Cui, S., Reinartz, P., 2014. Building Change Detection Based on Satellite Stereo Imagery and Digital Surface Models. Geosci. Remote Sensing, IEEE Trans. 52, 406-417. https://doi.org/10.1109/TGRS.2013.2240692 